\title{
Optimasi Klasifikasi Jenis Hutan Menggunakan Deep Learning Berbasis Optimize Selection
}

\author{
Rizki Tri Prasetio ${ }^{1}$, Endang Ripandi ${ }^{2}$ \\ ${ }^{1}$ Universitas BSI \\ email: rizki.rte@bsi.ac.id \\ ${ }^{2}$ Universitas BSI \\ email: endang12433@bsi.ac.id
}

\begin{abstract}
Abstrak
Hutan adalah paru-paru dunia, maka menjaga kelestarian hutan merupakan suatu keharusan. Menurut WWF (2015) bahwa lebih dari 170 hektar hutan di seluruh dunia akan menghilang secara pesat hingga tahun 2030 mendatang. Brian Johnson, Ryutaro Tateishi, dan Zhixiao Xie (2010) melakukan penelitian untuk mengklasifikasikan jenis populasi tumbuhan hutan pada hutan Ibraki, Jepang. Algoritma SVM (Support Vector Machine) dan MLP (Multy Layer Perceptron) diterapkan untuk mengklasifikasikan jenis populasi tumbuhan hutan di hutan Ibraki dengan hasil akurasi $85.9 \%$. Hasil Penelitian Brian Johnson dkk, diberi nama Forest Type Mapping Datasets. Hasil akurasi yang diperoleh dari penerapan algoritma SVM dan MLP masih belum mencapai hasil akurasi yang optimal dan masih mungkin untuk ditingkatkan. Untuk dapat meningkatkan hasil akurasi yang optimal terhadap klasifikasi jenis populasi tumbuhan hutan pada Forest Type Mapping Datasets, maka pada penelitian ini diusulkan untuk menerapkan algoritma optimasi fitur Optimize Selection pada algoritma Deep Learning. Hasil penelitian menunjukan bahwa metode yang diusulkan membuat peningkatan akurasi yang signifikan. Nilai akurasi klasifikasi pada jenis populasi tumbuhan hutan yang dihasilkan algoritma Deep Learning dengan optimasi fitur Optimize Selection berhasil meningkat menjadi $96.46 \%$.
\end{abstract}

Kata Kunci: Optimasi Klasifikasi, Deep Learning, Optimize Selection

\begin{abstract}
Forests are the lungs of the world, so preserving forests is a must. According to WWF (2015) that more than 170 hectares of forest in the whole world will disappear rapidly until the next 2030. Brian Johnson, Ryutaro Tateishi, and Zhixiao Xie (2010) conducted a study to classify the types of forest plant populations in the Ibraki forest, Japan. SVM (Support Vector Machine) and MLP (Multy Layer Perceptron) algorithms are applied to classify forest plant population types in the Ibraki forest with an accuracy of $85.9 \%$. The research results of Brian Johnson et al, were named the Forest Type Mapping Datasets. Accuracy results obtained from the application of the SVM and MLP algorithms still have not achieved optimal accuracy and are still possible to be improved. To be able to improve the optimal accuracy of results on the classification of forest plant population types in the Forest Type Mapping Datasets, in this study it was proposed to apply the Optimize Selection feature optimization algorithm in the Deep Learning algorithm. The results of the study show that the proposed method makes a significant increase in accuracy. The classification accuracy value on the type of forest plant population produced by the Deep Learning algorithm with optimization of Optimize Selection managed to increase to $96.46 \%$.
\end{abstract}

Keywords: Classification Optimization, Deep Learning, Optimize Selection

\section{Pendahuluan}

Informasi mengenai prediksi bahwa dunia akan kehilangan hutan pada tahun 2030 bila tren deforestasi atau penebangan hutan tidak segera dihentikan. Dunia patut waspada dan siap untuk kehilangan $80 \%$ wilayah hijaunya. Lebih dari 170 hektar hutan akan menghilang secara pesat hingga tahun 2030 mendatang (WWF, 2015). Menurut Rodney Taylor selaku Direktur Program Hutan WWF Internasional mengatakan bahwa sumber daya manusia 
perlu ditingkatkan untuk menciptakan sumber ekonomi hijau yang inovatif, cerdas dan bijak dalam memanfaatkan lingkungan, kemudian mengembalikan fungsi hutan. Hal ini jelas harus sangat diperhatikan karena hutan merupakan paru-paru dunia, bila tidak maka dunia akan kehilangan paru-parunya.

Terkait dengan permasalahan hutan, pada tahun 2010 Brian Johnson, Ryutaro Tateishi dan Zhixiao Xie dari Chiba University Jepang, Melakukan penelitian untuk mengetahui populasi tumbuhan atau pohon yang hidup di hutan khususnya hutan Negara Jepang. Penelitian dilakukan pada tiga musim yang berbeda yaitu pada 26 September 2010, 19 Maret 2011, dan 8 Mei 2011 yang mengamati melalui penginderaan jauh atau remote sensing orthorectified ASTER. Hasil pencitraan orthorectified ASTER digunakan sebagai data sampel untuk memisahkan spektral antara jenis pohon biasa dan pohon gugur. Areal hutan yang menjadi tempat penelitian tersebut terletak pada Pulau Honshu Jepang lebih tepatnya di wilayah Kanto Kota Prefektur Ibraki, Ibu Kota Mito (36o 57' N, 140o 38' E).

Penelitian difokuskan pada tumbuhan yang hanya hidup di daerah hutan tersebut. Tumbuhan yang diteliti adalah dua pohon dengan nama Cryptomeria japonica (Sugi) dan Chamaecyparis obtusa (Hinoki). Pohon sugi dan hinoki merupakan pohon endemik Hutan Jepang yang menjadi salah satu komuditas ekspor yang sangat penting bagi Negara Jepang. Hasil dari penelitian yang dilakukan pada tahun 2010 hingga 2011 ini dikenal dengan nama Forest Type Mapping Dataset.

\section{Metode Penelitian}

Data mining merupakan teknologi baru yang sangat berguna untuk perusahaanperusahaan menemukan informasi yang sangat penting dari gudang data mereka. Beberapa aplikasi Data mining fokus pada prediksi, mereka meramalkan apa yang akan terjadi dalam situasi baru dari data yang menggmbarkan apa yang terjadi dimasa lalu (Witten \& Frank, 2011). Data mining merupakan bagian dari Knowledge Discovery Data (KDD) yang merupakan proses ekstraksi informasi yang berguna, tidak diketahui sebelumnya dan tersembunyi dari data (Bramer, 2013) dan juga mengembangkan model yang digunakan untuk memahami fenomena dari analisis data dan prediksi (Maimon dan Rokach, 2010).

Data mining merujuk pada ekstraksi pengetahuan dari jumlah data yang besar (Han \& Kamber, 2006) yang tersimpan dalam komputer, proses pada Data mining lebih banyak berdasarkan pada teknologi informasi (Olson dan Delen, 2008). Secara umum tugas Data mining dapat diklasifikasikan menjadi dua kategori yaitu deskriptif dan predktif (Handayana \& Wahono, 2012). Tugas pertambangan deskriptif mengkarakterisasi sifat umum data dalam database. Pertambangan deskriptif digunakan untuk membuat prediksi (Han \& Kamber, 2006).

Berikut adalah tahapan Data mining dalam proses penemuan pengetahuan seperti yang terlihat pada Gambar 2.4 (Han \& Kamber, 2006) :

a. Pembersihan data, dilakukan untuk menghilangkan noise dan data tidak konsisten.

b. Integrasi data, dimana beberapa sumber data dapat dikombinasikan.

c. Data seleksi, dimana data yang relevan dengn tugas analisis database akan diambil.

d. Data transformasi, dimana data diubah atau dikonsolidasi kedalam bentuk yang sesuai untuk pertambangan dengan melakukan operasi ringkasan atau agregasi.

e. Data mining, proses mengidentifikasi pola yang benar-benar menarik yang mewakili pengetahuan didasarkan pada beberapa langkah-langkah interestingness.

f. Pengetahuan presentasi, dimana visualisasi dan teknik representasi pengetahuan digunakan untuk menyajikan pengetahuan kepada pengguna.

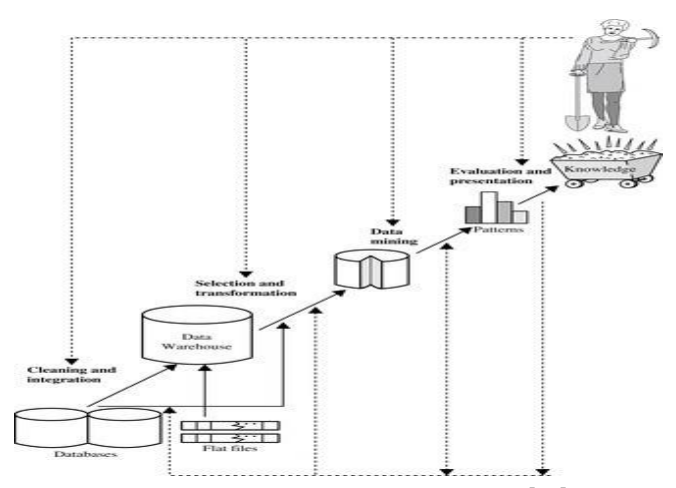

Gambar 1. Tahapan Data mining 
Terdapat empat kelompok dalam Data mining menurut Written, Frank, dan Hall (Handayana \& Wahono, 2012) :

a. Klasifikasi

Proses klasifikasi didasarkan pada kelas dan variabel dependen. Model klasifikasi yang populer adalah Decision Tree, Naïve Bayes, Neural Networks, Genetic Algorithm, dan Support Vector Machine.

b. Asosiasi

Pada prinsipnya, penemuan aturan asosiasi mempelajari aturan bagaimana memahami peroses identifi kasi aturan antara ketergantungan yang berbeda dari fenomena kelompok. Dengan demikian tujuan asosiasi adalah untuk mencari hubungan objek berdasarkan aturan untuk memprediksi terjadinya objek berdasarkan kejadian lain.

c. Clustering

Cluster adalah proses menemukan kelompok objek berdasarkan kemiripan, sehingga setiap kelompok mempunyai perbedaaan antara satu dengan yang lainnya.

d. Prediksi

Prediksi merupkan proses yang berkaitan dengan kemampuan untuk memprediksi tanggapan terbaik (output) yang paling dekat dengan kenyataan berdasarkan input data.

Dengan demikian, semakin kecil perbedaaan atara apa yang diharapakan terjadi (hasil yang diharapakan) dan apa yang sebenarnya terjadi (hasil yang diamati), semakin baik prediksi, contohnya prediksi ramalan cuaca (misalnya, untuk 24 atau 48 jam) atau diagnosis untuk penyakit tertentu yang diberikan kepada pasien tertentu, yang didasarkan pada data medis (Gorunescu, 2011).

Konsep data mining, menemukan pola berharga dalam data, adalah respon yang jelas untuk pengumuan dan penyimpanan volume data yang besar (Weiss, Indurkhya, \& Zhang, 2010). Secara khusus, koleksi metode yang dikenal sebagai 'data mining' menawarkan metodologi dan solusi teknis untuk mengatasi analisis data medis dan konstruksi dari prediksi (Bellazzi, dan Zupan, 2008). Untuk semua aplikasi data mining, akurasi prediksi tergantung pada kualitas prediksi atribut (Weiss, Indurkhya, dan Zhang, 2010).

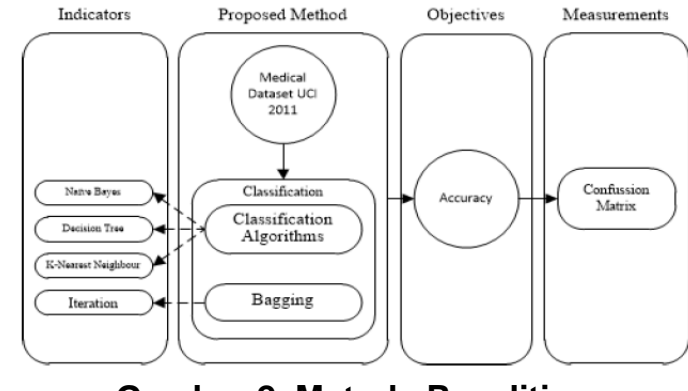

Gambar 2. Metode Penelitian

Data yang digunakan untuk training data dan testing data pada penelitian kali ini merupakan data sekunder yang telah dikumpulkan dan dianalisis oleh peneliti sebelumnya dan telah melalui tahap-tahap Data mining. Untuk menguji model klasifikasi yang tepat pada tipe pemetaan hutan, maka digunakan Forest Type Mapping Dataset (Johnson, Tateishi, \& Xie, 2012). Dataset tersebut telah dipublikasi dan didokumentasi pada website Unversity of California Irvine Machine Learning Data Repository (UCl Machine Learning Repository).

Pada tahap ini, dibutuhkan eksplorasi terhadap Forest Type Mapping Dataset. Eksplorasi bertujuan untuk memastikan semua atribut-atribut dan kelas-kelas dalam dataset tersebut valid dan dapat digunakan sebagai objek penelitian. Sehingga tujuan untuk mengetahui hasil klasifikasi terbaik dari tipe pemetaan hutan dapat dicapai.

a. Populasi

Populasi dari Forest Type Mapping Dataset adalah kelas pada data itu sendiri dan terbagi menjadi empat populasi atau kelas, yaitu $S$ (populasi pohon sugi), $\mathrm{H}$ (populasi pohon hinoki), $\mathrm{D}$ (populasi pohon campuran), dan $\mathrm{O}$ (populasi pohon lainnya).

b. Sample

Sample digunakan untuk pengujian terhadap model yang dihasilkan atau dapat dikatakan sebagai testing data, sedangkan training data berfungsi sebagai bahan pelatihan suatu model. Forest Type Mapping Dataset memiliki total record sebanyak 523, kemudian telah dibagi menjadi dua bagian, yaitu 325 record digunakan sebagai training data dan 198 record digunakan sebagai testing data. 
Forest Type Mapping Dataset adalah data sekunder yang sudah siap untuk proses data mining. Metode yang akan diterapkan adalah metode yang sudah diterapkan oleh para peneliti-peneliti yang menggunakan dataset ini sebagai objek penelitian mereka sebelumya. Forest Type Mapping Dataset sudah didesain melalui semua tahapan yang diperlukan sebagai dataset untuk model klasifikasi (Classifier Model).

Pada tahap ini, dibutuhkan eksplorasi dari datasets yang digunakan. Langkah pertama adalah diketahui bahwa tujuan utama yang ingin dicapai adalah untuk mengetahui hasil klasifikasi dari pemetaan jenis hutan yang terbaik.

a. Sampling

Pada penelitian ini menggunakan Forest Type Mapping datasets dengan jumlah 523 record. Untuk menguji model yang dikembangkan, data akan dibagi menjadi dua bagian, yaitu training data dan testing data. Training data digunakan untuk pengembangan model, dan Testing data digunakan untuk menguji model. Diketahui bahwa jumlah seluruh data adalah 523 record kemudian telah dibagi menjadi dua bagian, 325 record digunakan sebagai training data dan 198 record digunakan sebagai testing data atau sebagai data sampel.

b. Seleksi Fitur

Untuk dapat meningkatkan hasil akurasi sampai nilai akurasi yang maximal salah satunya adalah dengan penerapan optimasi seleksi fitur. Pada penelitian kali ini akan diterapkan optimasi seleksi fitur berbasis Optimize Selecion pada setiap model yang telah diuji coba. Optimize Selecion memilki prinsip mencari dan memilih fitur-fitur dari yang memiiki nilai terbaik dari seluruh subset. Proses seleksi fitur pada Optimize Selecion dapat terlihat pada gambar berikut.

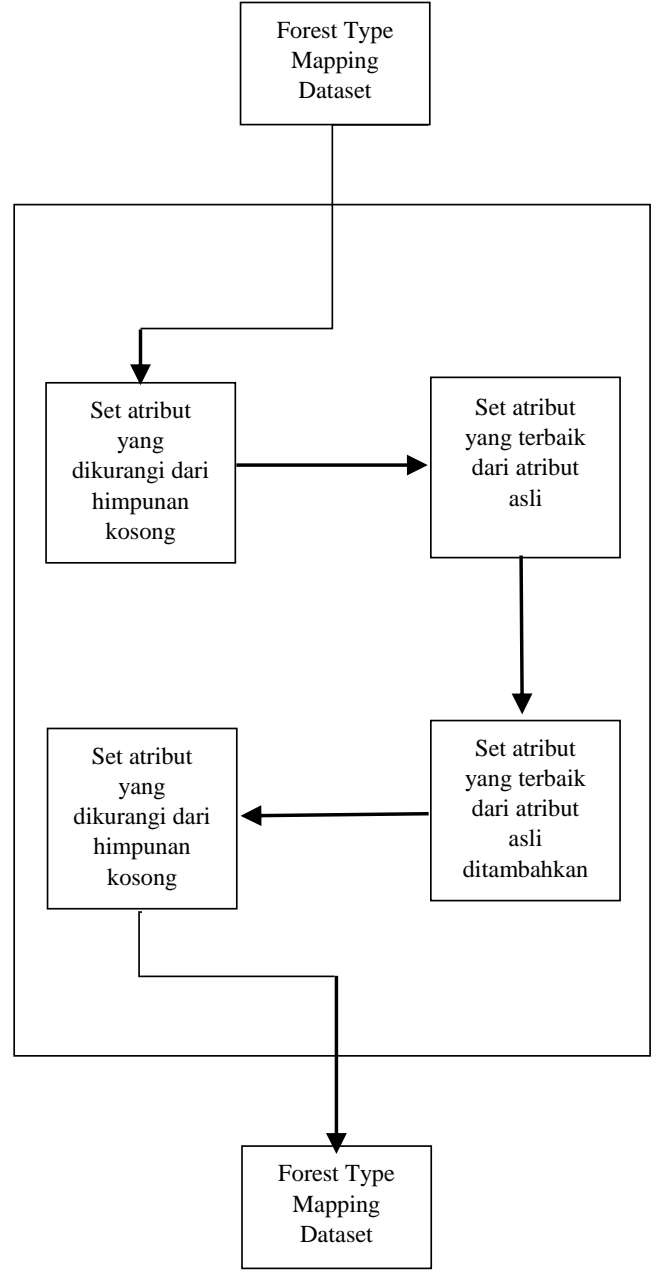

Gambar 3. Metodologi Optimize Selecion

\section{Hasil dan Pembahasan}

Penerpan algoritma Deep Learning dengan optimasi fitur seleksi Optimize Selection pada Forest Type Mapping Dataset dimaksudkan untuk dapat meningkatkan hasil akurasi pada klasifikasi jenis populasi hutan dari hasil penelitianpenelitian sebelumnya. Peningkatan hasil akurasi akan diraih atau tidak, hasilnya akan terihat pada hasil eksperimen. Eksperimen pada algoritma Deep Learning akan dilakukan dalam dua tahap. Eksperimen tahap pertama adalah eksperimen terhadap algoritma Deep Learning tanpa penerapan optimasi fitur Optimize Selection dan eksperimen yang kedua adalah eksperimen terhadap algoritma Deep Learning dengan Penerapan Optimize Selection.

a. Hasil Eksperimen Deep Learning tanpa Optimize Selection 
Pada tahap ini adalah proses eksperimen tahap pertama yaitu pengujian model menggunakan Software Rapidminer terhadap model Deep Learning tanpa berbasis Optimize Selection. Foret Type mapping dataset yang merupakan dataset yang telah disiapkan untuk diimplementasikan pada proses uji model, kemudian diujikan pada algoritma Deep Learning tanpa Optimize Selection. Setelah dilakukan uji model maka diperoleh hasil seperti pada tabel 1.

Tabel 1. Hasil akurasi model Deep Learning berbasis Optimize Selection

\begin{tabular}{|c|l|c|}
\hline No & Model (Algoritma) & Akurasi \\
\hline 1 & Deep learning & $83.84 \%$ \\
\hline
\end{tabular}

Pada tabel 1 hasil akurasi yang diperoleh untuk kelasifikasi jenis populasi hutan dari Forest Type Mapping Dataset belum mencapai harapan yaitu belum memperoleh hasil maksimal. Hasil tersebut masih dibawah dari hasil akurasi dari algoritma yang digunakan pada penelitianpenelitian sebelumnya. Maka dari hasil tersebut pada penelitian kali ini akan diterapkan optimasi seleksi fitur untuk dapat meningkatkan hasil akurasi pada hasil model Deep Learning berbasis Optimize Selection seperti yang telah diungkapkan pada model yang diusulkan.

\section{b. Hasil Eksperimen Deep Learning}

Berbasis Optimize Selection

Pada tahap ini akan dilakukan eksperimen dengan penerapan optimasi seleksi fitur Optimize Selection pada model Deep Learning. Optimize Selection adalah satu optimasi seleksi fitur yang dapat memilih atribut-atribut terbaik sehingga dapat mampu meningkatkan tingkat akurasi pada subset yang diujikan. Setelah eksperimen dilakukan maka hasilnya dapat terlihat pada tabel 2.

Tabel 2. Hasil akurasi model Deep Learning berbasis Optimize Selection

\begin{tabular}{|c|c|c|}
\hline No & Model (Algoritma) & Akurasi \\
\hline 1 & $\begin{array}{l}\text { Deep learning } \\
\text { Optimize Selection }\end{array}$ & $96.46 \%$ \\
\hline
\end{tabular}

Pada tabel 2 hasil akurasi yang diperoleh dengan penerapan Optimize Selection untuk kelasifikasi jenis populasi hutan di hutan Ibraki telah berhasil meningkat. Maka terbukti bahwa algoritma Optimize Selection mampu meningkatkan tingkat akurasi hingga $96.46 \%$ dari yang sebelumnya $83.34 \%$ yang dihasilkan model Deep Learning tanpa Optimize Selection. Optimasi seleksi fitur berbasis Optimize Selection mampu meningkatkan akurasi sebesar $13.12 \%$ dari hasil yang diperoleh algoritma Deep Learning tanpa Optimize Selection.

Pada tahap ini adalah tahap untuk mengevaluasi hasil dari eksperimen yang dilakukan pada eksperimen tahap satu dan eksperimen tahap dua. Kedua eksperimen dilakukan pada Software Rapidminer v7.5 yang sudah terimplementasi model Classifier Deep Learning with $\mathrm{H} 2 \mathrm{O}$ Algorithm. Pada eksperimen tahap satu diperoleh hasil yang belum maksimal, kemudian pada tahap kedua hasil akurasi dapat meningkat.

a. Perbandingan Algoritma Deep Learning dengan Algoritma lain

Untuk mengevaluasi apakah hasil akurasi dari algoritma Deep Learning tanpa Optimize selection ini adalah yang terbaik, apabila dibandingkan dengan model-model Classifier yang lain. Evaluasi ini bertujuan hanya untuk melihat apakah ada algoritma Classifier yang lain yang mampu memperoleh hasil akurasi yang lebih optimal dibandingkan dengan Deep Learning atau apakah justru Deep Learning memperoleh hasil yang lebih rendah. Evaluasi masih tetap dilakukan pada Software yang sama setelah pengujian dengan model Deep Learning selesai dilakukan. Hasil perbandingan algoritma Deep Learning Dengan Algoritma yang lain dapat terlihat pada tabel 3 .

Tabel 3. Perbandingan Deep Learning dengan Algoritma lain

\begin{tabular}{|c|l|c|}
\hline No & Model (Algoritma) & Akurasi \\
\hline 1 & Deep learning & $83.84 \%$ \\
\hline 2 & k-NN & $88.38 \%$ \\
\hline 3 & Naïve Bayes (Kernel) & $77.95 \%$ \\
\hline 4 & Random Forest & $85.35 \%$ \\
\hline 5 & $\begin{array}{l}\text { Generalize Linear } \\
\text { Model }\end{array}$ & $89.39 \%$ \\
\hline
\end{tabular}


Pada tabel 3 dapat terlihat hasil akurasi dari seluruh algoritma yang dieavaluasikan dengan algoritma Deep Learning. Dari tabel tersebut algoritma Deep Learning adalah algoritma dengan hasil perolehan yang paling rendah. Maka pada hasil evaluasi ini algoritma Deep Learning bukanlah Algoritma yang terbaik. Perolehan akurasi dari algoritma Deep Learning tanpa Optimize Selection sebesar $83.84 \%$ lebih rendah dibandingkan hasil akurasi yang diperoleh algoritma Generalize Lnear Model yaitu sebesar $89.39 \%$. Menurut penelitian yang dilakukan oleh Fitriyani dan Wahono pada tahun 2015 bahwa Optimasi Seleksi Fitur Optimize Selection dapat meningkatkan hasil akurasi pada subset dengan pemilihan atribut yang memiliki nilai terbaik. Maka Optimize Selection akan diterapkan pada model Deep Learning dengan tujuan untuk dapat meningkatkan hasil akurasinya.

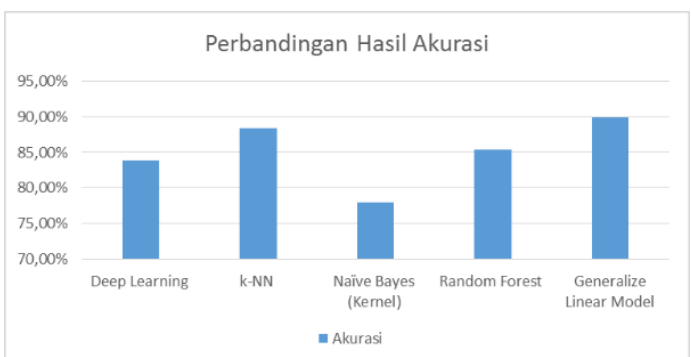

\section{Gambar 4. Grafik hasil evaluasi tanpa Optimize Selection}

\section{Kesimpulan}

Pada peneltian ini dilakukan Eksperimen terhadap algoritma Deep Learning berbasis Optimize Selection untuk mengkelasifikasi dataset Forest Type Mapping. Algoritma Deep Learning yang secara umum merupakan algoritma turunan dari Neural Network yang dipadukan dengan optimasi seleksi fitur berbasis Optimize Selection, bertujuan untuk dapat mengoptimasi nilai akurasi klasifikasi jenis populasi tumbuhan hutan di hutan Ibraki, Jepang. Berdasarkan hasil eksperimen pada penelitian ini, maka dapat ditarik kesimpulan sebagai berikut :
1. Algoritma Deep Learning yang
dikombinasi dengan algoritma $\mathrm{H} 2 \mathrm{O}$ memiliki kelengkapan metode dalam Machine Learning baik secara supervised learning maupun unsupervised learning. Untuk

membuktikan seberapa baik algoritma tersebut maka dilakukan eksperimen pada algoritma Deep Learning. Eksperimen pertama dilakukan tanpa berbasis Optimize Selection, dengan nilai akurasi yang dihasilkan sebesar $83.84 \%$. Hasil tersebut merupakan hasil yang belum optimal dibanding hasil akurasi pada penelitian sebelumnya. Untuk dapat meningkatkan hasil akurasi, maka dilakukan eksperimen yang kedua yaitu dengan berbasis Optimize Selection, maka diperoleh nilai akurasi sebesar $96.46 \%$. Hasil tersebut bukan hanya meningkatkan nilai akurasi pada eksperimen pertama tapi juga meningkat dari hasil akurasi yang diperoleh pada penelitian-penelitian sebelumnya.

2. Optimize Selection merupakan salah satu optimasi seleksi fitur yang dapat meningkatkan suatu nilai akurasi pada nilai maksimal melalui pemilihan fitur terbaik. Optimize Selection yang dikombinasikan dengan Deep Learning terbukti menjadi kombinasi yang sangat baik. Nilai akurasi dari klasifikasi jenis populasi tumbuhan hutan yang diberi nama Forest Type Mapping Dataset berhasil meningkat.

Pada penelitian kali ini hanya terbatas pada eksperimen algoritma Deep Leaning yang berbasis Optimize Selection dan analisa nya terhadap hasil eksperimen tersebut, dan tidak mengimplementasikan algoritma tersebut menjadi sebuah aplikasi.

1. Pada penelitian berikutnya bisa dilakukan eksperimen pada algoritma Deep Learning dengan penerapan algoritma optimasi seleksi fitur yang lain, untuk menguji apakah Algoritma Deep Learning masih memiliki performa terbaik dan mampu meningkatkan nilai akurasi dari algoritma lainnya.

2. Mengimplementasikan Algoritma Deep Learning kedalam sebuah aplikasi misalnya dengan menggunakan bahasa pemerograman Web maupun bahasa pemerograman Desktop.

\section{Referensi}

Akhtar, F., \& Hahne, C. (2012). Rapidminer v7.5 "Operator Reference". Diambil 
Kembali dari Rapid-I GmbH: www.rapid-i.com

Alfisahrin, S. N. (2012). Komparasi Algoritma C4.5, Naïve Bayes dan Neural Network Untuk Memprediksi Penyakit jantung. Jakarta: Pasca Sarjana Megister IImu Komputer SSTMIK Nusa Mandri.

Arno Candel, E. L. (2016). Deep Learning with $\mathrm{H} 2 \mathrm{O}$. Deep Learning with H2O, 1.

Bellazi, R., \& Zupan, B. (2008). Predictive Data mining In Clinical Medicine : Curent Issues And Guidelines. International Journal Of Medical Informatics7, 81-97.

Bengio, Y., \& Glorot, X. (2010). Undertandig The Diificulty of Training Deep Feedforward Neural Networks. Deep Neural Network.

Candel, A., LeDell, E., Parmar, V., \& Arora, A. (2017). Deep Learning with $\mathrm{H} 2 \mathrm{O}$. California: H2O.ai, Inc.

Fitriyani dan wahono, R. S. (2015). Integrasi Bagging dan Greedy Forward Selection Pada Prediksi Cacat Software dengan menggunakan Naive Bayes. Journal of Software Engineering, Vol. 1, No. 2, 101.

Gorunecu, F. (2011). Data mining Concepts, Models and Techniques. Berlin: Springer.

Han, J., \& Kamber, M. (2006). Data mining Concepts and Techniques Second Edition. San Francisco: Diane Cerra.

Handyana, F., \& Wahono, R. S. (2012). Penerapan Particle Swarm Optimization Untuk Seleksi Atribut Pada Metode Support Vector Machine Untuk Prediksi Penyakit Diabetes. Jurnal Ilmiah Program Pasca Sarjana Magister IImu Komputer STMIK Nusa Mandiri.

Johnson, B., Tateishi, R., \& Xie, Z. (2012). USING GEOGRAPHICALLY WEIGHTED VARIABLES FOR IMAGE CLASSIFICATION. Remote Sensing Letters Vol. 3, No. 6, 491-499.

KODANI, J. (2006). Ecologi and management of conifer plantations in Japan: control of free growth and maintenance of biodiversity. Journal Of Forest Research, 11, pp. 267-274.

Kusrini, E. T. (2009). Algoritma Data Mining. Yogyakarta: Andi.

Kusumadewi, S. (2004). Membangun Syaraf Tiruan Menggunakan Matlab \& Excel Link. Yogyakarta: Graha Ilmu.
Larose, D. (2006). Data mining Methods and Models. Hoboken, New Jersey: John Wiley \& Sons, Inc.

Maimon, O., \& Rokach, L. (2010). Data mining and Knowledge Discovery Handbook Second Edition. New York: Springer.

Olson, D., \& Delen, D. (2008). Advance Data mining Techniques. Berlin: Springer.

Permana, H., \& Riana, D. (2015). KOMPARASI ALGORITMA C4.5, NAIVE BAYES, DAN NEURAL NETWORK UNTUK KLASIFIKASI JENIS HUTAN DENGAN PENERAPAN ALGORITMA GENETIKA. Jurnal Ilmiyah.

prabook. (2017, Juni 5). http://prabook.com/web/person-

view.html. Retrieved from prabook.com: http://prabook.com/web/personview. html?profileld $=618773$

Prasetya, T. (2012). Penggunaan Algoritma Greedy Dalam Permanan Warcraft III Tower Defence . Makalah IF3051 Strategi Algoritma , 5.

Sabanci, K., Unlersen, M., \& Polat, K. (2016). CLASSIFICATION OF DIFFERENT FOREST TYPES WITH MACHINE LEARNING ALGORITHMS . ReseaRch foR RuRal Development 2016, volume $1,254-260$.

Taylor, R. (2015, April 30). National Geographic. Retrieved from National Geographic Indonesia: http://nationalgeographic.co.id

Van Aarsten, J. p. (1953). ekonomi pertanian Indonesia. California: Pembangunan 1953.

Vercellis, C. (2009). Business Intelligence: Data mining And Optimization for Decision Making. Cornwall: John Wiley \& Sons, Ltd.

Weiss, S., Indurkhya, N., \& Zhang, T. (2010). Fundamentals of Predictive Text Mining. London: Springer.

WWF. (2015, april 30). National Geographic Indonesia. Retrieved from National Geographic:

http://nationalgeographic.co.id 